\title{
Spine Loss in Primary Somatosensory Cortex during Trace Eyeblink Conditioning
}

\author{
Bettina Joachimsthaler, ${ }^{1,2,4}$ Dominik Brugger, ${ }^{1,2}$ Angelos Skodras, ${ }^{3,5}$ and $\mathbb{C}$ Cornelius Schwarz ${ }^{1,2}$ \\ ${ }^{1}$ Werner Reichardt Center for Integrative Neuroscience, Systems Neuroscience, ${ }^{2}$ Hertie Institute for Clinical Brain Research, Department of Cognitive \\ Neurology, ${ }^{3}$ Hertie Institute for Clinical Brain Research, Department of Cellular Neurology, ${ }^{4}$ Graduate School of Neural and Behavioural Science, and \\ ${ }^{5}$ German Center for Neurodegenerative Diseases, Eberhard Karls University, 72076 Tübingen, Germany
}

\begin{abstract}
Classical conditioning that involves mnemonic processing, that is, a "trace" period between conditioned and unconditioned stimulus, requires awareness of the association to be formed and is considered a simple model paradigm for declarative learning. Barrel cortex, the whisker representation of primary somatosensory cortex, is required for the learning of a tactile variant of trace eyeblink conditioning (TTEBC) and undergoes distinct map plasticity during learning. To investigate the cellular mechanism underpinning TTEBC and concurrent map plasticity, we used two-photon imaging of dendritic spines in barrel cortex of awake mice while being conditioned. Monitoring layer 5 neurons' apical dendrites in layer 1, we show that one cellular expression of barrel cortex plasticity is a substantial spine count reduction of $\sim 15 \%$ of the dendritic spines present before learning. The number of eliminated spines and their time of elimination are tightly related to the learning success. Moreover, spine plasticity is highly specific for the principal barrel column receiving the main signals from the stimulated vibrissa. Spines located in other columns, even those directly adjacent to the principal column, are unaffected. Because layer 1 spines integrate signals from associative thalamocortical circuits, their column-specific elimination suggests that this spine plasticity may be the result of an association of top-down signals relevant for declarative learning and spatially precise ascending tactile signals.
\end{abstract}

Key words: barrel column; spine plasticity; trace eyeblink conditioning; trained mice; two-photon imaging

\section{Introduction}

Rodent barrel cortex, the primary sensory area receiving tactile signals from the animals' vibrissae, is characterized by separated columnar representations of individual whiskers. Because this feature allows for the manipulation of tactile input in spatially highly precise ways, it makes barrel cortex an excellent tool with which to study cortical plasticity. The defining elements of these columns are the layer 4 barrels originating from structural characteristics of granular cells and sensory afferents that carry signals predominantly from one whisker. Sensory deprivation studies have shown that plastic changes in the barrel cortex are present during adulthood and are highly specific, leading either to the expansion of barrels representing intact whiskers or to the shrinkage of barrels that receive inputs from sensory-deprived whiskers (Diamond et al., 1994; Fox, 2002). Long-term synaptic

Received May 20, 2014; revised Jan. 12, 2015; accepted Jan. 18, 2015.

Author contributions: B.J. and C.S. designed research; B.J., D.B., and A.S. performed research; D.B. and A.S. contributed unpublished reagents/analytic tools; B.J. and C.S. analyzed data; B.J. and C.S. wrote the paper.

B.J. was supported by a PhD scholarship granted by the German Helmholtz Research Center for Neurodegenerative Diseases (DZNE). This work was supported by Deutsche Forschungsgemeinschaft SCHW 577/12-1. We thank Marcel Oberlaender and Matthias Jucker for sharing valuable thoughts on the results and conclusions of this work and Ursula Pascht for excellent technical assistance.

The authors declare no competing financial interests.

Correspondence should be addressed to Cornelius Schwarz, Werner Reichardt Center for Integrative Neuroscience, Systems Neurophysiology, University Tübingen, Otfried Müller Str. 25, 72076 Tübingen, Germany. E-mail: cornelius.schwarz@uni-tuebingen.de.

DOI:10.1523/JNEUROSCI.2043-14.2015

Copyright $\odot 2015$ the authors $\quad 0270-6474 / 15 / 353772-10 \$ 15.00 / 0$ plasticity, or changes of synaptic gain, have been linked successfully to this map plasticity (Feldman et al., 1999). Further, structural cellular plasticity is expressed as changes in spine number (Grutzendler et al., 2002; Trachtenberg et al., 2002; Holtmaat et al., 2005; Zuo et al., 2005a, 2005b; Yang et al., 2009; Hübener and Bonhoeffer, 2010) and associated presynaptic terminals (Knott et al., 2002; Trachtenberg et al., 2002; Yamahachi et al., 2009; Oberlaender et al., 2012b).

The studies cited so far investigated sensory deprivation or enrichment and thus focused on sensory processing with gross alteration of neural input. However, arguably, the most important function of cortex (including primary sensory cortices) is the association with other cortical areas for cognitive and/or mnemonic functions (Feldmeyer et al., 2013). In contrast to sensory deprivation/enrichment, such processes are characterized by unchanged mean input activity but altered top-down signaling determined to reroute task-relevant signaling pathways. Fitting this conjecture, primary sensory cortices have been shown to play a role in classical conditioning, but only if a mnemonic aspect is present; that is, the "trace" period interspersed between the presentations of conditioned stimulus (CS) and unconditioned stimulus (US; Kraus and Disterhoft, 1982; Weinberger et al., 1993). Mnemonic aspects and cortical involvement are accompanied by processes with decidedly cognitive flavor: Disrupting CS-US pairings (i.e., presenting CS alone) in trace-conditioned human probands leads to an increment of CR probability, whereas the reverse, a decrement in response probability, was 
seen in probands trained on a delay paradigm (Clark et al., 2001). Therefore, the absence of paired presentation seemed to be overwritten by declarative knowledge and awareness in those probands who learned to associate the stimuli using a memory trace, whereas it remained a more simple function of the frequency of pairing in those who learned the association without engaging mnemonic functions.

Fitting the general notion of involvement of cognitive functions and cortical activity in trace conditioning, mouse barrel cortex has explicitly been shown to play a critical role for acquisition and retention of vibrissae-based, tactile trace eyeblink conditioning (TTEBC). Lesions of barrel cortex entirely block learning and temporarily impair retention. In contrast, the performance of mice trained on "delay" eyeblink conditioning, a variant of the task in which CS and US overlap, thus rendering mnemonic processes dispensable, is all but unaffected by barrel cortex lesions (Galvez et al., 2007). Using cytochrome oxidase histology in rabbits and mice, these investigators further showed that TTEBC leads to a spatially specific extension of the row of barrels that receive the CS input (Galvez et al., 2006), whereas training on tactile delay eyeblink conditioning leaves the barrel map unchanged (Galvez et al., 2011). In the present study, we sought to investigate the correlate of the distinct map plasticity during trace learning on the cellular level monitoring turnover of dendritic spines. We were interested in determining whether spine plasticity occurs during trace conditioning and if it would be spatially specific to the barrel columnar map. We found that spines on apical dendrites of layer 5 cells in layer 1 imaged in awake, head-fixed mice undergo a substantial spine loss during trace learning in parallel with the barrel column extension known from the earlier studies cited above. Importantly, the spine loss in layer 1 was confined to the principal barrel column, making barrel cortex an ideal tool with which to study spatially specific rearrangement of cortical networks during associative learning.

\section{Materials and Methods}

Animals. All experimental and surgical procedures were performed in accordance with guidelines of animal use of the Society for Neuroscience and German Law (approved by the Regierungspräsidium Tübingen). Adult male C57BL/6 mice expressing YFP in layer 5 pyramidal neurons (H-line; Feng et al., 2000) were bred and group housed under pathogenfree conditions. After surgery, animals were housed individually with food and water ad libitum under an inverted $12 \mathrm{~h}$ light/dark cycle.

Surgery. To obtain permanent optical access, we performed cranial window implantations over the right barrel cortex (Holtmaat et al., 2009) under general anesthesia (fentanyl $0.05 \mathrm{mg} / \mathrm{kg}$, midazolam $5 \mathrm{mg} / \mathrm{kg}$, medetomidine $0.50 \mathrm{mg} / \mathrm{kg}$, i.p.). The skull over the barrel cortex was removed, leaving the dura mater intact. A sterile, round coverslip was then gently pushed onto the brain tissue using a custom-made post mounted onto a micromanipulator until it formed a plane with the surrounding bone and was then sealed to the skull with light-curing dental cement. Subsequently, a custom-made titanium ring $(0.7 \mathrm{~g}, 14 \mathrm{~mm}$ diameter; Hefendehl et al., 2012) was placed over the cranial window so that the animal could be fixed under the two-photon microscope. After suturing the skin to enclose the ring, anesthesia was terminated by an antidote (naloxon $1.20 \mathrm{mg} / \mathrm{kg}$, flumazenil $0.50 \mathrm{mg} / \mathrm{kg}$, atipamezol $2.50 \mathrm{mg} / \mathrm{kg}$, s.c.). Analgesia was assured by carprofen $(0.05 \mathrm{mg} / \mathrm{kg} / \mathrm{d}$, s.c. for $3 \mathrm{~d})$. All animals were allowed to recover from surgery for at least 1 week before the experiment was started.

Intrinsic signal imaging. Intrinsic imaging was used to functionally map the location of the CS-activated barrel column (Masino et al., 1993). Here, we followed largely the procedures and used the software (Helioscan) devised by Langer et al. (2013). Images were captured using a CCD camera (Teli CS3960DCL; Toshiba Teli, 12 bit depth resolution, $300 \times 300$ pixel) equipped with a macro adapter $(6.5 \mathrm{~mm})$, a macro extensor $(25 \mathrm{~mm})$, and a macro iris controlled via a camera link card (PCI-1426, National Instruments). First, the blood vessel pattern was captured under green light $(570 \mathrm{~nm})$ to serve as a reference. Second, for the acquisition of the intrinsic optical signal, monochromatic red light $(630 \mathrm{~nm})$ was used and the CCD camera was focused at a cortical depth of $200-250 \mu \mathrm{m}$. Single whisker stimulation (60 Hz sine wave, rostrocaudal amplitude $0.7 \mathrm{~mm}$ at $5 \mathrm{~mm}$ distance from the face) was conducted by inserting the whisker into a small glass capillary $(0.58 \mathrm{~mm}$ inner diameter) glued to a piezo bender. A measurement (sweep) consisted of 3 image acquisition phases each lasting for $5 \mathrm{~s}$. Whisker stimulation was applied exclusively in the last phase. Frames were acquired over 20 sweeps (frame rate: $20 \mathrm{~Hz}, 300 \times 300$ pixel; spatial resolution: $17.4 \mu \mathrm{m} /$ pixel, field of view area: $5.23 \times 5.23 \mathrm{~mm}^{2}$ ). For each time point relative to the start of a phase, an image with the relative difference between the first and last two phases were calculated. Difference images were averaged over the duration of a phase and over sweeps, resulting in a control image and an image carrying the intrinsic signal. The activated area by single whisker deflection was automatically traced by boxcar filtering the image (kernel $10 \times 10$ pixel), followed by normalization of the range of captured gray values to $[0,255]$ and adjusting a threshold of gray values to capture an activation area approximately the diameter of a barrel $(300 \mu \mathrm{m})$.

Trace eyeblink conditioning. Mice were habituated to the head fixation and the experimental setup under the 2-photon microscope for at least 2 weeks before training (Schwarz et al., 2010). Classical conditioning was conducted using a 250-ms-long single sinusoidal deflection to whisker E1 as CS $(60 \mathrm{~Hz}$ sine wave, $0.7 \mathrm{~mm}$ rostrocaudal deflection at $5 \mathrm{~mm}$ distance from the left side of the face). The CS was followed by a $250 \mathrm{~ms}$ stimulus-free trace interval before the US was applied to the center of the right eye for $50 \mathrm{~ms}$ in the form of a corneal air puff (Picospritzer III; Parker). White noise sound $(75 \mathrm{~dB})$ was present throughout the training session to mask potential acoustic emissions of the whisker stimulator. Eyeblinks were monitored using a custom-made infrared reflective optic sensor (Weiss and Disterhoft, 2008) that translated the closure of the eyelid into a voltage signal.

In two preliminary experiments using TTEBC in trained mice that did not enter the present dataset of spine counts, the voltage readout of the sensor was calibrated to the millimeter scale using high-speed videography ( $100 \mathrm{~Hz}$ frame rate, MC1362; Microtron). The camera was equipped with a $100 \mathrm{~mm}, 2.8 \mathrm{f}$ objective lens (AT-X Pro for Nikon) mounted on a C-mount adapter and was controlled by MotionBLITZ camera software (Microtron). Videos of conditioned eyelid responses were analyzed manually by measuring the number of pixels between the eye lids vertically across the pupil (ImageJ; Fig. 1 A,B). Video data were aligned to behavioral data and simultaneously performed voltage measurement using the infrared sensor by placing an LED light in the visual field of the camera that reported US onset. Correlating videographically measured lid closure with the voltage readout of the infrared sensor revealed a robust linear relationship between the two measures, allowing us to interpret the infrared optic measurements as relative eye closure (with respect to a baseline) in millimeters after calibrating with the videography data (Fig. 1C).

A conditioned response (CR) was defined as an eye closure exceeding 5 SDs of eyelid motion captured during a baseline interval $[-20,0] \mathrm{ms}$ relative to CS onset and generating eye closure velocities $>1 \mu \mathrm{m} / \mathrm{ms}$ in the interval $[0,500] \mathrm{ms}$ relative to CS onset (i.e., during CS presentation and subsequent trace period). Only responses that persisted until the last $15 \mathrm{~ms}$ before US onset were accepted as CR. Trials in which animals elicited spontaneous blinks [larger than a fifth of the mean unconditioned reflex response (UR) amplitude seen in the same session] within $150 \mathrm{~ms}$ before the onset of the CS were excluded from the analysis. One group of mice was trained on paired CS-US presentation ("test mice," $n=6$, in which only the E1 barrel column was imaged, and additionally $n=3$ in which the E1, E2, and B1 barrel columns were imaged). In the test condition, one session consisted of 60 trials ( 53 paired presentations of CS and US and 7 trials with CS alone) separated by a mean intertrial interval of $30 \mathrm{~s}$ (random pick from a flat probability distribution ranging from 20 to $40 \mathrm{~s}$ ). A second group of mice underwent pseudoconditioning ("control mice," $n=6$ ). Control mice received 60 whisker deflections and 53 US air puff presentations exactly as the test mice, but 
A
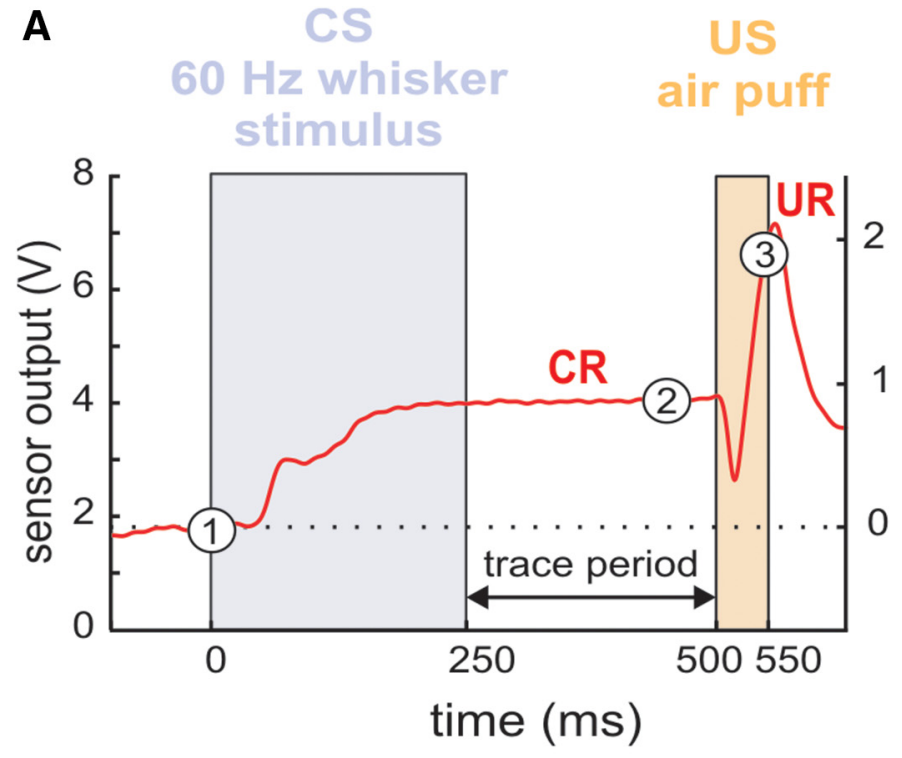

B

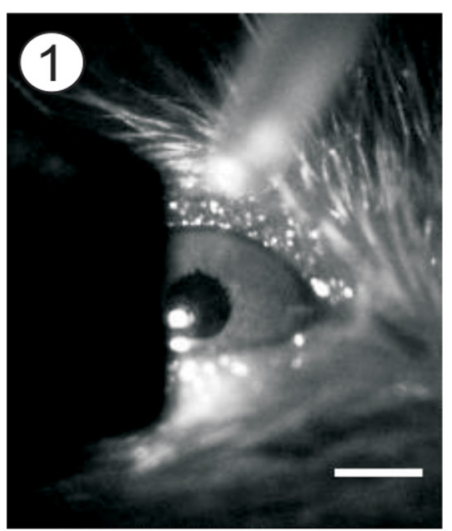

US air puff

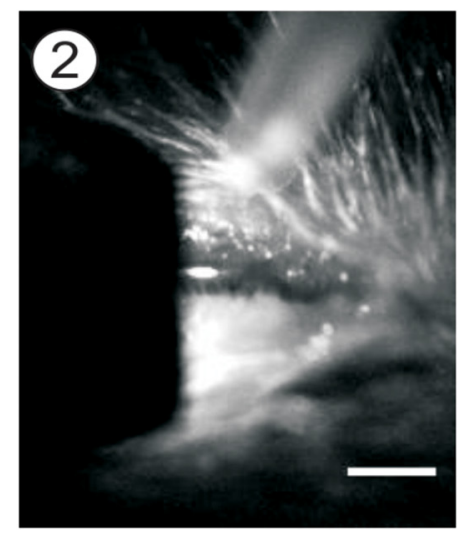

C
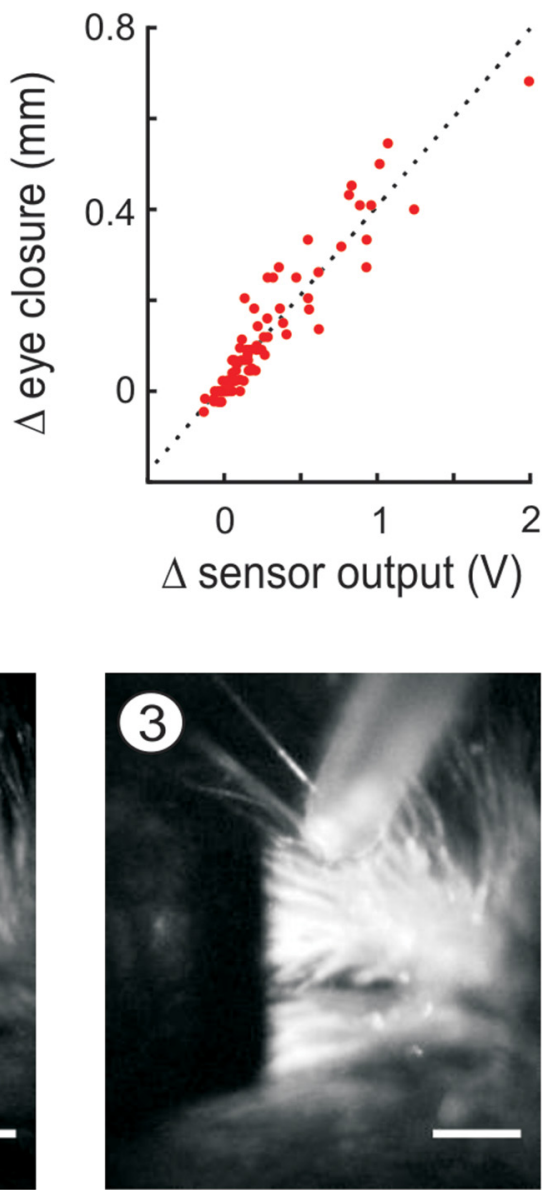

Figure 1. TTEBC in head-fixed mice. $A$, Example trial of TTEBC recorded from a trained animal. The CS and US intervals are marked as violet and orange boxes. The trace period is interspersed between $C S$ and US. The CR is an eye closure (measured as the distance between upper and lower lid, red curve), which starts typically during $C S$ presentation and is kept until the US evokes the reflexive UR (a full eye closure; axis label of the right ordinate pertains also to the ordinate of $\boldsymbol{C}$. $\boldsymbol{B}$, Frames from a high-speed camera ( $100 \mathrm{~Hz}$ frame rate) acquired at three time points during the trial shown in $\boldsymbol{A}$ (marked as numbers on the red curve): (1) open eye measured at $0 \mathrm{~ms}$, (2) partially closed eye at $450 \mathrm{~ms}$, and (3) fully closed eye at $550 \mathrm{~ms}$. Scale bar, $1 \mathrm{~mm}$. C, Calibration of the infrared eye blink detector using videography: relative eye closure $(\Delta \mathrm{mm})$ measured via high-speed videography and corresponding relative voltage change $(\Delta \mathrm{V})$ measured with the infrared sensor show high correlation (Pearson correlation: $r=0.94$, best linear fit: $y=0.39 x+0.017$ ). The slope of the regression line was used to calculate relative eye closure in millimeters from the voltage output of the sensor (zero was set to baseline position of the eye lids just before the CS onset (cf. $A$ ).

in a random sequence with a mean intertrial interval of $15 \mathrm{~s}$ (random pick from a flat probability distribution ranging from 10 to 20 s). Both groups of animals were trained once a day on 5 subsequent days. Individual sessions lasted for $\sim 30 \mathrm{~min}$. Five CS and US presentations (CS-US pairings in test mice, separated CS and US presentations in control mice) were delivered before the start of the session to adjust the position of the optic sensor and the air puff outlet.

In vivo two-photon imaging. Awake mice entered a restrainer box (a rescaled version of the one described previously for rats; Schwarz et al., 2010) and subsequently were head-fixed by fitting the implanted titanium ring in a clamp connected to a motorized XY-stage (Luigs \& Neumann; Hefendehl et al., 2012). The head fixation system was installed under the objective lens, making it possible to rapidly relocalize previously imaged regions of interest with a precision of a few micrometers. Two-photon imaging was performed using a Leica DMLFS microscope equipped with a TCS 238 SP2 scan head (Leica) and a Spectra Physics Mai-Tai BB laser. Neuronal structures were imaged using an excitation wavelength of $910 \mathrm{~nm}$. Detection of the YFP signal was performed using non-descanned detectors (R6357 P.M.T.; Hamamatsu) through a 40 HCX APO water-immersion objective (0.8 numerical aperture; Leica). The average power delivered to the brain was $<45 \mathrm{~mW}$. Apart from baseline sessions, imaging was performed immediately after the training sessions in awake animals. $Z$-stacks of areas containing dendrites and dendritic spines of interest (apical tuft within the patch of intrinsic optical signal) in layer 1 (median depth: $60 \mu \mathrm{m}$, range; $49-87 \mu \mathrm{m}$ ) were acquired at high resolution $(1024 \times 1024$ pixels, pixel size: $0.098 \mu \mathrm{m}, 0.5$ $\mu \mathrm{m} z$ step size, stack size: $20-30 \mu \mathrm{m})$.

Data analysis. Data analysis was performed blind to training conditions. For image processing, first, a motion correction algorithm was applied using a hidden Markov model (adapted from Dombeck et al., 2007) to compensate for minor $X-Y$ displacements induced by movements and breathing of the animal. Furthermore, imaged stacks were deconvolved using Autoquant X (Media Cybernetics). ImageJ software was used to measure background fluorescence. Dendritic appendages with fluorescence intensities smaller than 5 -fold the SD of the background fluorescence and shorter than $0.5 \mu \mathrm{m}$ were not counted.

Spines were counted using a custom-written MATLAB script, which allowed semiautomated alignment of individual dendrites of the 3D stacks for each imaging session and therefore facilitated to follow spines across imaging days. Spines were counted regardless of their shapes, including filopodia-like structures. 
A

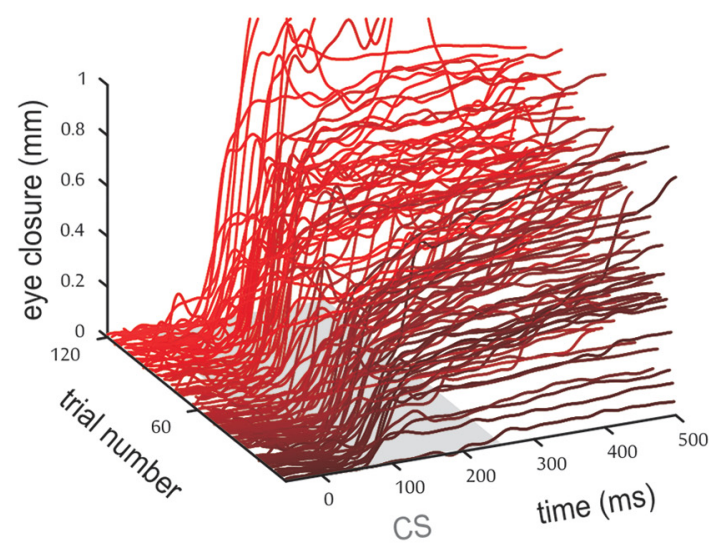

B

mouse \#4

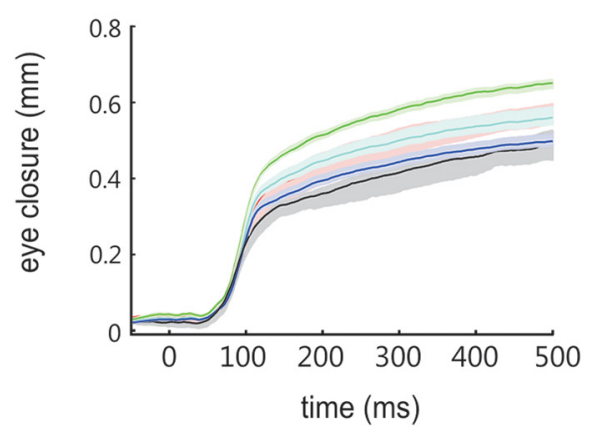

mouse \#6

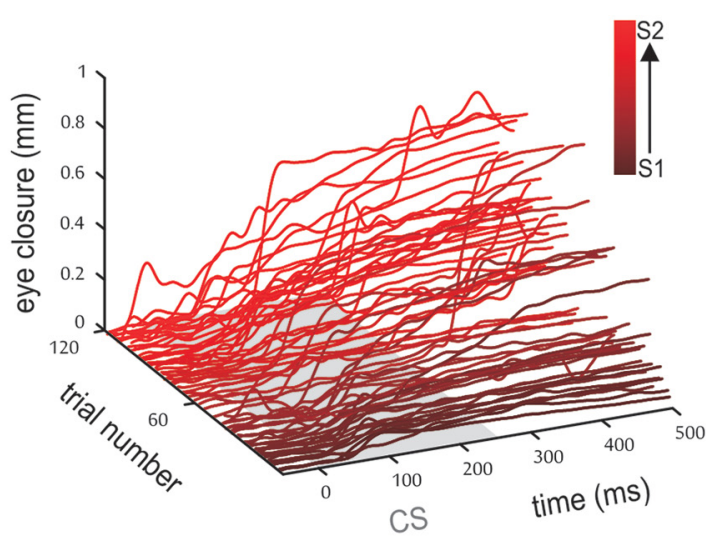

mouse \#6

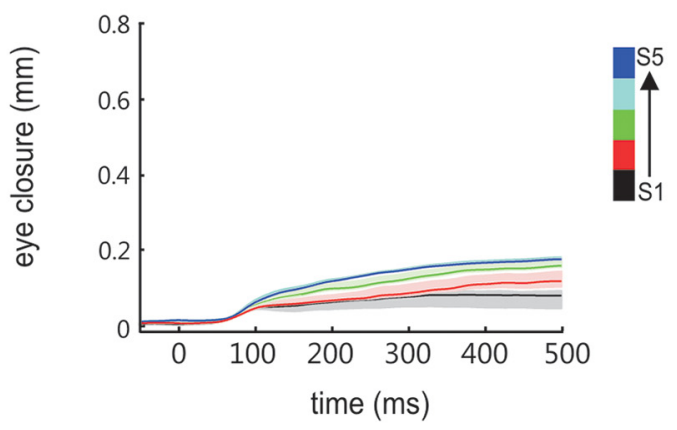

Figure 2. Conditioned responses. A, Eye closure traces recorded in two animals (font colors fit the lines in Fig. $3 A$ ) during the acquisition of the TTEBC task. The CRs that occurred during the first 120 trials (sessions $S 1$ and $\mathrm{S} 2$ ) are shown (traces run from $20 \mathrm{~ms}$ before $\mathrm{CS}$ to the end of the trace period; for purposes of illustration, the earlier trials are colored darker than the later ones). Note that animals received five $(S$ and US presentations before the start of the session to adjust the position of the optic sensor and the air puff outlet (see Materials and Methods). $\boldsymbol{B}$, Mean eye closure ( \pm SEM) plotted across trial time as observed in each of the five training sessions ( $\mathrm{S} 1-\mathrm{S} 5$, colored black to blue) for the animals shown in $\boldsymbol{A}$.

Table 1. Overall behavior and spine changes after five training sessions

\begin{tabular}{|c|c|c|c|c|c|c|c|c|}
\hline$\overline{\text { Mouse }}$ & Column monitored & Valid trials & No. of CRs & $\%$ CRs & Spines before training & No. of lost spines & No. of gained spines & $\%$ Change in spine no. \\
\hline \multicolumn{9}{|c|}{ Test group $(n=9)$} \\
\hline 1 & E1 & 282 & 181 & 64 & 50 & 20 & 9 & -20 \\
\hline 2 & E1 & 281 & 170 & 60 & 53 & 13 & 5 & -13 \\
\hline 3 & E1 & 286 & 200 & 70 & 69 & 22 & 8 & -19 \\
\hline 4 & E1 & 287 & 271 & 94 & 63 & 17 & 9 & -11 \\
\hline 5 & E1 & 290 & 150 & 52 & 76 & 32 & 15 & -21 \\
\hline 6 & E1 & 293 & 197 & 67 & 58 & 21 & 8 & -22 \\
\hline 7 & E1 & 294 & 145 & 49 & 64 & 19 & 10 & -13 \\
\hline 8 & E1 & 294 & 148 & 50 & 82 & 24 & 10 & -17 \\
\hline 9 & E1 & 291 & 119 & 41 & 72 & 11 & 5 & -9 \\
\hline \multicolumn{9}{|c|}{ Test-adjacent group $(n=6)$} \\
\hline 7 & B1 & 294 & 145 & 49 & 86 & 5 & 8 & 4 \\
\hline 8 & B1 & 294 & 148 & 50 & 75 & 3 & 5 & 3 \\
\hline 9 & B1 & 291 & 119 & 41 & 62 & 5 & 7 & 2 \\
\hline 7 & E2 & 294 & 145 & 49 & 63 & 14 & 8 & 4 \\
\hline 8 & E2 & 294 & 148 & 50 & 51 & 7 & 8 & 1 \\
\hline 9 & E2 & 291 & 119 & 41 & 50 & 6 & 7 & 1 \\
\hline \multicolumn{9}{|c|}{ Control group ( $n=6$ ) } \\
\hline 10 & E1 & 291 & 44 & 15 & 90 & 12 & 15 & 3 \\
\hline 11 & E1 & 283 & 67 & 24 & 65 & 6 & 6 & -1 \\
\hline 12 & E1 & 270 & 56 & 21 & 63 & 9 & 7 & -3 \\
\hline 13 & E1 & 298 & 40 & 13 & 39 & 7 & 6 & -1 \\
\hline 14 & E1 & 175 & 17 & 10 & 94 & 13 & 12 & 0 \\
\hline 15 & E1 & 295 & 60 & 20 & 137 & 40 & 36 & -4 \\
\hline
\end{tabular}

Stimulated whisker was always E1. Statistical test of percent change in spine numbers (last column in table): medians: test: $-17 \%$; control: $-1 \%$; test-adjacent (B1 and E2): $2.5 \%$. Rank-sum U test significance levels: test versus control, $p<0.001$; control versus test, adjacent, $p>0.01$; test versus test, adjacent, $p<0.001$. 


\section{Results}

We trained head-fixed mice on TTEBC, a classical conditioning paradigm that consists of the paired presentation of a tactile CS (a $60 \mathrm{~Hz}$ sinusoidal deflection of the E1 whisker for $250 \mathrm{~ms}$ ) followed by an US (a $50 \mathrm{~ms}$ corneal air puff) separated by a stimulusfree trace period of $250 \mathrm{~ms}$ (Fig. 1A). Nine test mice well habituated to head fixation received 265 contingent CS/US presentations and 35 unpaired CS presentations in 5 daily sessions (53 paired and $7 \mathrm{CS}=60$ trials per day, mean intertrial interval $=$ $30 \mathrm{~s}$ ). Six control mice were presented with the same number of unpaired CS and US (mean intertrial interval $=15 \mathrm{~s}$ ). The air puff was adjusted such that it was sufficiently strong to elicit a robust UR (i.e., a full closure of the eye), but was chosen soft enough that the mice kept their eyes open between trials (Fig. 1B). Eyelid closure was measured as the vertical gap between the upper and lower eyelids (Fig. 1B,C). Spontaneous eye closure within an interval $500 \mathrm{~ms}$ before CS onset invalidated the trial. Learning of the stimulus association was indicated by the generation of eyelid closure upon presentation of the CS, the so-called CRs. The learning performance shown in Figure $2 A$ presents representative eyelid trajectories of two animals during CS and the subsequent trace period obtained in the first two conditioning sessions (i.e., the first 120 trials). CRs were characterized by a consistent latency of eyelid closure onset at $\sim 100 \mathrm{~ms}$ following CS onset, a feature distinct from the more delayed CRs generated by rabbits. Such short CR onset latencies have been observed in basically all studies conducted so far in mice (Tseng et al., 2004; Weiss and Disterhoft, 2008) and also in studies that focused on the more variable latency of peak eyelid closure, which, at least in the delay task, is timed to occur at the US onset (Chettih et al., 2011; Heiney et al., 2014). Latencies $\sim 100 \mathrm{~ms}$ may well match what has been called the "short latency response" (Boele et al., 2010), a response component that has been suggested to partially resist cerebellar lesions and may receive some drive from the amygdala (Sakamoto and Endo, 2010). Finally, we observed stable or ramping eye lid closure until the US arrives, which likely corresponds to cerebellum and forebrain-dependent CRs in rabbits (Kalmbach et al., 2009).

The amplitude of the CRs was variable between trials and animals (partly due to variable degrees of eye opening between the trials in different animals) and also had a tendency to increase during the first three sessions (Fig. $2 B$ ). To capture these variable CRs reliably, we used an amplitude criterion relative to baseline eye position of minimally $5 \times$ the SD upward of the baseline position that had to be crossed to be counted as a CR. With this regime, we obtained minimally 270 and maximally 298 valid trials across five sessions in our sample of 15 mice. One control mouse could only be monitored for three behavioral sessions (175 valid trials) before it had to be taken out of the experiment because of health reasons not related to the experimental procedures (Table 1). Control mice, which were subjected to the same number of CS/US presentations, but in non-contingent fashion, generated spontaneous eyeblinks during the $500 \mathrm{~ms}$ after CS onset in $<24 \%$ of the trials, whereas all test animals approached substantially higher values of $41-94 \%$ (Fig. 3A, Table 1). Importantly, the distribution of latencies measured from the test mice peaked at $\sim 100 \mathrm{~ms}$ after CS onset, as mentioned above, whereas the spontaneous blinks generated by control mice were evenly distributed across CS and trace periods (Fig. 3B). The worst learner among the test mice exceeded the maximum $C R$ rate observed in control mice in session 3, but most learning curves of test mice separated from those of control animals well before,
A

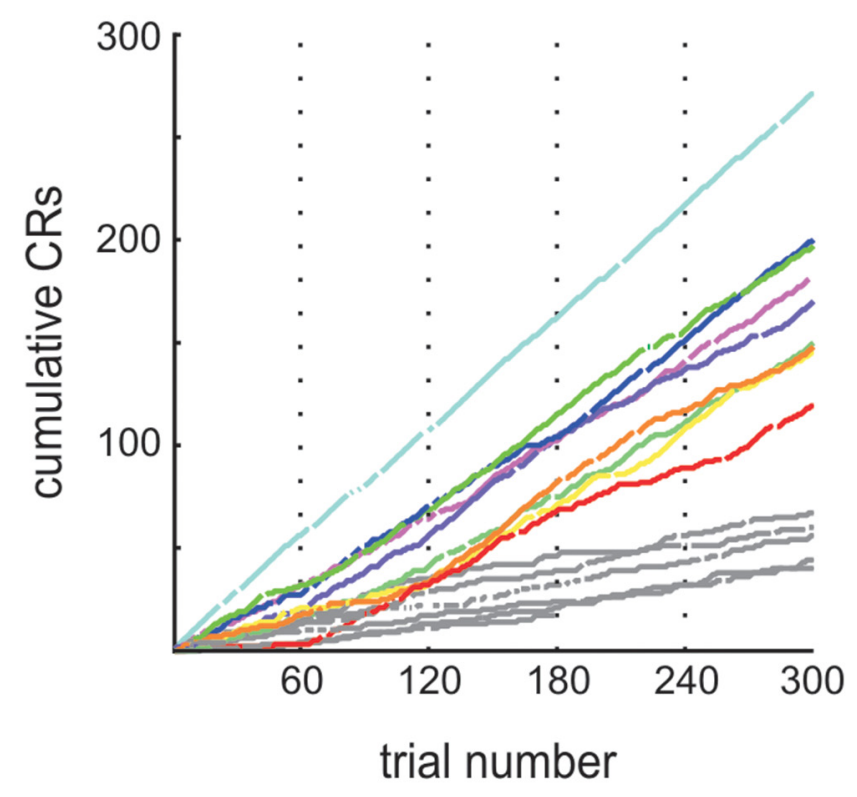

B

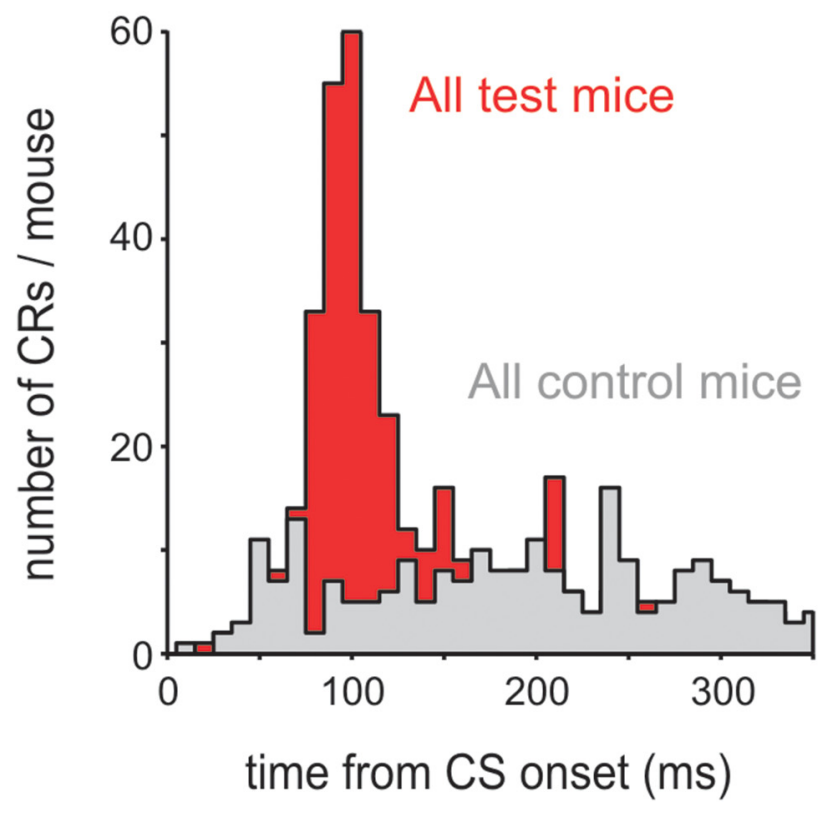

Figure 3. Behavioral performance. $A$, Cumulative CR count across all training sessions ( $\mathrm{S} 1-$ S5) plotted across trials (gaps in the curves indicate invalid trials because of blinking in the interval 500 ms before (S onset; vertical dotted lines separate training sessions). Each colored line plots the cumulative learning curve of one test animal. Data from control animals are plotted in gray. $\boldsymbol{B}$, Histogram of CR latencies observed in nine test mice (red) and six control mice (gray).

typically already in the first session. The learning performance of our mice observed using the presentation of CS and US on opposite sides of the face are comparable to results obtained with presentation on the same side (Galvez et al., 2007, 2011), indicating that the neuronal system underlying eyeblink conditioning is organized bilaterally.

We combined TTEBC with chronic two-photon imaging of dendritic spine plasticity. Dendritic spines were visualized by using transgenic mice that express YFP in cortical layer 5 neurons 
A intrinsic imaging two-photon imaging conditioning pseudoconditioning
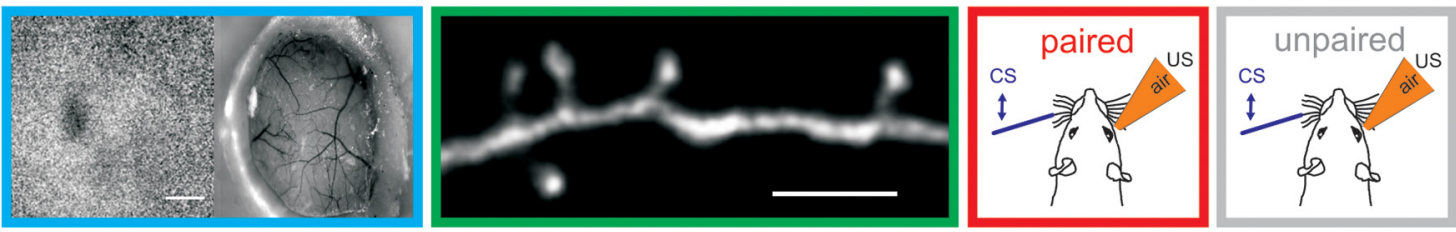

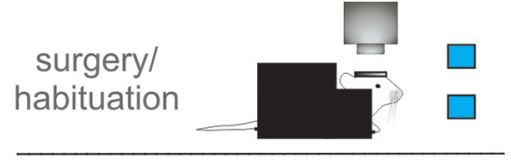

timeline

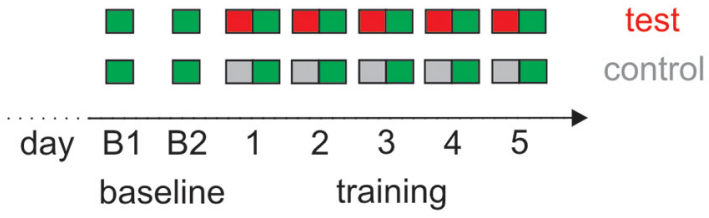

B

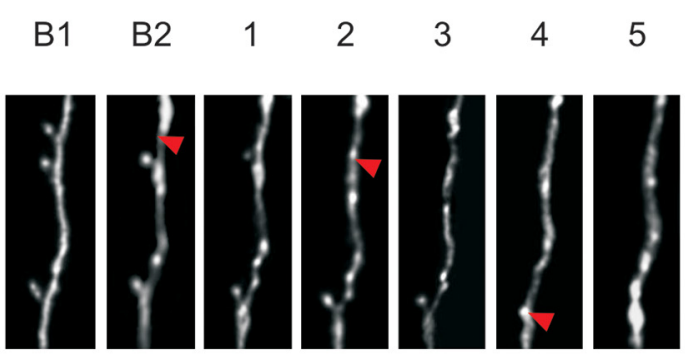

spine lost
C

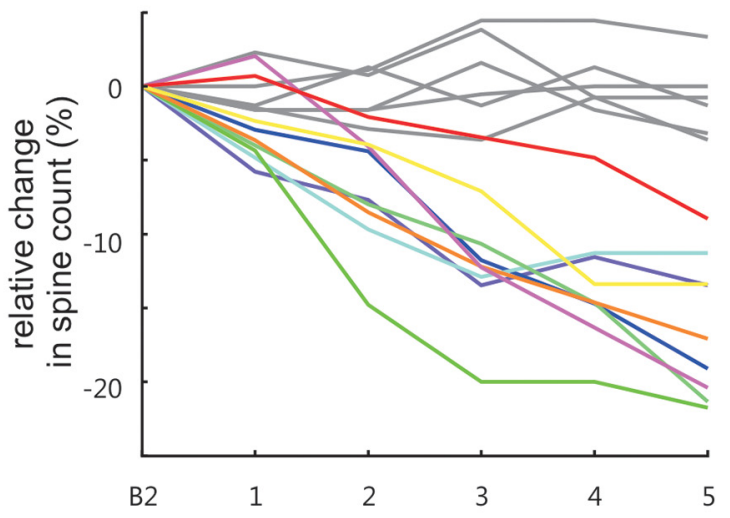

session number

Figure 4. Learning related spine loss on layer 5 pyramidal dendrites in layer 1.A, Experimental strategy. Mice underwent chronic cranial window surgery. After recovery and habituation to head fixation, the responsive field on the cortical surface corresponding to stimulated whisker E1 was monitored using intrinsic imaging (blue boxes). Scale bar, $1 \mathrm{~mm}$. In 2 baseline and 5 training sessions performed on 7 subsequent days, 2-photon imaging visualized dendritic spines in the E1 barrel column as characterized by intrinsic imaging (green boxes). Scale bar, $5 \mu \mathrm{m}$. After two baseline imaging sessions, test animals were trained on TTEBC (red boxes, paired CS and US) and control animals received pseudo-conditioning (gray boxes, unpaired CS and US). $\boldsymbol{B}$, Example dendritic segment imaged in an animal that underwent TTEBC as observed in the two baseline (B1, B2) and five training sessions (S1-S5). Red arrowheads indicate lost spines. $C$, Relative change in spine count across five training sessions plotted with reference to the mean of baseline sessions B1 and B2. Percent reduction in spine count in test and control animals are depicted by lines colored correspondingly to those in Figure $3 \mathrm{~A}$.

(H-line; Feng et al., 2000). All 15 animals were equipped with chronic cranial windows, allowing visual access to the barrel cortex (Holtmaat et al., 2009; Hefendehl et al., 2012). The barrel column of whisker E1 was reliably identified using intrinsic optical signal imaging (Langer et al., 2013; Fig. 4A). Dendritic spines on apical tufts of labeled layer 5 pyramidal neurons located within the CS activated cortical representation were imaged for 7 consecutive days in 2 daily baseline sessions (B1, B2) and then after 5 daily conditioning sessions (S1-S5; Fig. 4A). Stacks of images were taken from the head-fixed awake mice under the two-photon microscope immediately after the training session. With this regime, we were able to exclude possible anesthesia effects on spine dynamics. Figure $4 B$ shows an example of the daily record of a spiny dendrite in a test animal. The main effect to be analyzed in the following sections was a substantial reduction in spine numbers related to learning of the task.

The decrement in spine number was observed in test mice but not in control mice. Plotting change in spine count relative to the baseline sessions yielded a mirror image to the observed learning curves. The spine count in test animals systematically descended to $-9 \%$ to $-22 \%$ after the last training session, whereas in con- trol mice, the relative counts fluctuated around the baseline value, indicating no change (for detailed values and statistics, see Fig. 4C, Table 1). Importantly, the two distributions of relative spine numbers after training were completely nonoverlapping. We also counted absolute numbers of eliminated spines. The separation of test and control groups was clearly visible using eliminated spine counts as well (Table 1), but it was less clear compared with overall spine reduction. It turned out that the reason for this was a variability of general spine turnover across animals, consisting of balanced spine elimination and formation; that is, whenever there was a large basic spine elimination, it was matched by a respective higher basic spine formation (Table 1).

To extract the relationship of learning and spine loss, we had to cope with the problem that the two processes did not proceed simultaneously. Rather, spine loss seemed to follow learning with a certain delay. We therefore defined the time of learning as the trial in which the test animals first reached a CR rate of $>50 \%$ ( 5 of 9 trials) tested in a moving window across trials. All test animals reached this criterion of learning within the first 80 trials and sustained it for the rest of the training (Fig. 5A), whereas control mice did not (three control mice reached the criterion 
A

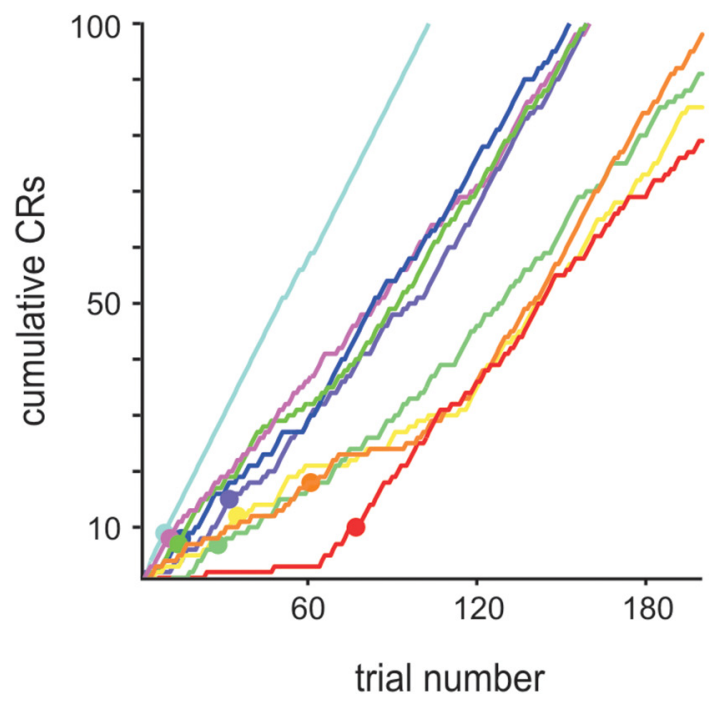

B

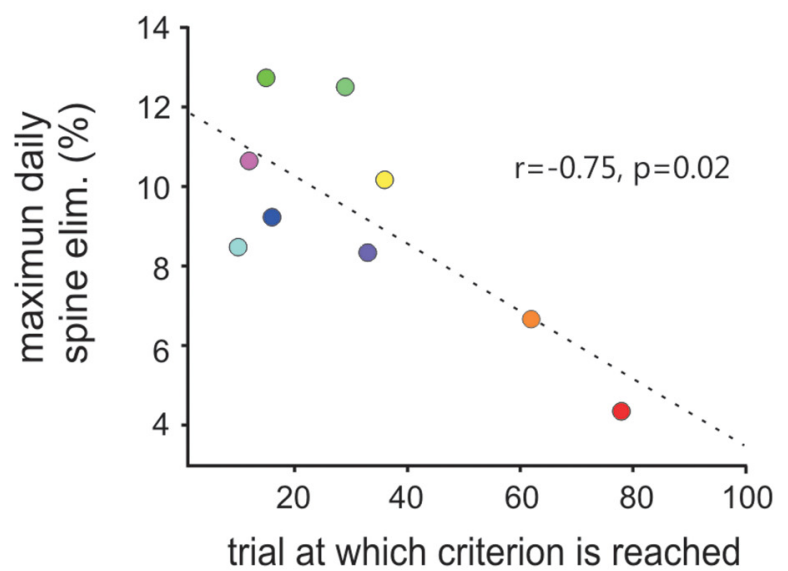

C

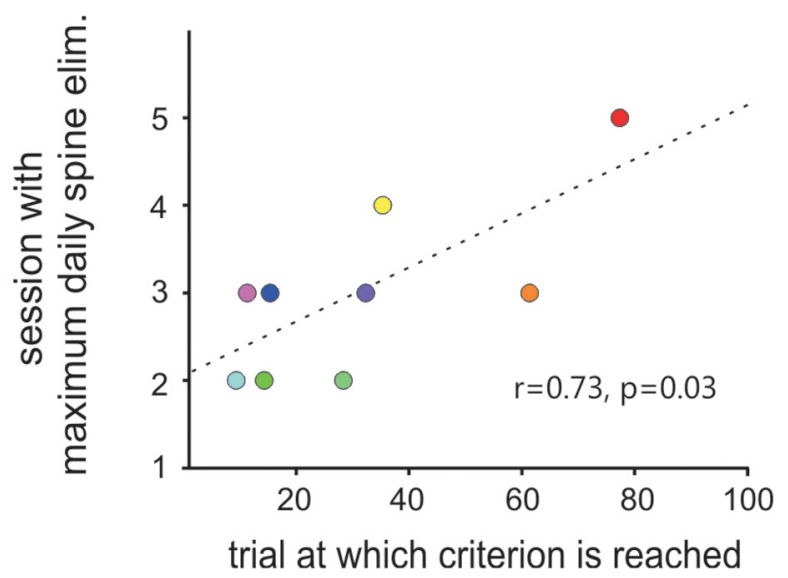

Figure 5. Correlation of spine loss with progress of learning. $\boldsymbol{A}$, Learning criterion. The curves are the same data shown as in Figure $3 A$, but plotted across the first 200 valid trials. Trials at which the learning criterion (five out of nine consecutive trials with (Rs) was reached are marked by a filled circle and correspond to what can be called the speed of learning. Maximum spine elimination measured per session $(\boldsymbol{B})$, as well as the number of session at which peak spine elimination is reached $(\boldsymbol{C})$, are correlated with the speed of learning. Broken lines in $\boldsymbol{B}$ and $C$ represent the best linear fit. Pearson correlation coefficient and significance level are indicated. Colors in the three panels correspond to those in Figures $3 A$ and $4 C$. once by chance but never sustained it). We regressed time of learning with the maximum spine loss observed in one session and found a strong negative correlation $(r=-0.75, p=0.02)$; that is, the faster the animal reached learning criterion, the higher was its peak spine loss (Fig. 5B). Similarly, the regression between the criterion trial and the number of the session in which peak spine elimination was observed resulted in a strong correlation $(r=0.73, p=0.03$; Fig. $5 C)$. Because nine samples is a small number for regression analysis, we sought to validate the correlations found by showing that they were invariant with systematic variation of the criterion. Indeed, criterion number and window length in wide ranges of [2-15] (criterion) of [4-60] (window) yielded robust correlation coefficients between 0.5 and 0.7 for maximum spine reduction and 0.6 and 0.8 for the number of sessions as long as the trial numbers needed to reach criterion performance spread out within the first 2 training sessions. The intersection of the regression line with the ordinate in Figure $5 C$ indicates that the delay of the maximum spine elimination was approximately two sessions after the animals reached learning criterion. It needs to be born in mind, however, that learningrelated spine elimination imposed itself as a fast process: in seven of nine test mice, spine reduction separated from the range seen in control mice already after the first session; that is, in these animals, spine elimination took over within a time span of $\sim 45$ $\min$ (the duration of the session plus the time to image the dendrites). In summary, these results provide a strong indication that task acquisition and spine loss are tightly related: nonlearners (the control group) lacked a loss of spines, whereas time of learning in the test mice was correlated with time and magnitude of spine loss.

Finally, we were interested in determining whether the observed reduction in spine numbers is specific to the barrel column associated to the stimulated vibrissa. In a subset of three test mice, we monitored E1 (the principal barrel column, as before) and in addition investigated spine dynamics in the adjacent E2 and B1 barrel columns (Table 1). Because the E2 column is immediately adjacent to the principal column E1, it was taken care in this case that dendrites were chosen for imaging that were not located in the overlap zone of the intrinsic signals indicating the two barrel columns. For dendrites within B1, this was of no concern because, typically, the two areas of enhanced intrinsic signal did not overlap. The localization of dendrites with respect to the area of elevated intrinsic signal was reconstructed using the surface vessels imaged during the two-photon and during the intrinsic imaging session (Fig. 6A). Strikingly, spine reduction was found only within the E1 representation, but neither the adjacent column E2 nor the farther distant column B1 showed any spine loss different from controls. Representative examples of E1 and E2 dendrites are shown in Figure 6B. Quantification of relative reduction of spine numbers confirmed this impression. Relative spine counts in barrel column E1 were significantly reduced (as shown before), whereas spine counts in E2 and B1 were indistinguishable from those seen in control animals (Fig. $6 C$; for statistics, see Table 1).

\section{Discussion}

Our study shows that the trace-dependent map plasticity in barrel cortex is correlated with a reduction in spine numbers on layer 5 neuron's apical tuft in layer 1 . Together with previous electron microscopic evidence that spine elimination is associated with physical detachment of presynaptic terminals from the dendrite (Trachtenberg et al., 2002), this argues strongly in favor of the hypothesis that synapses connecting to apical tufts in layer 5 pyramids are pruned during TTEBC. The functional significance of 
A
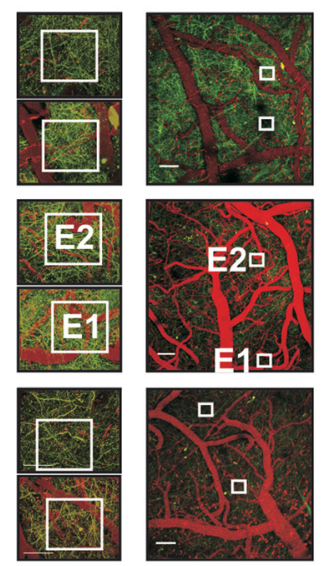

B
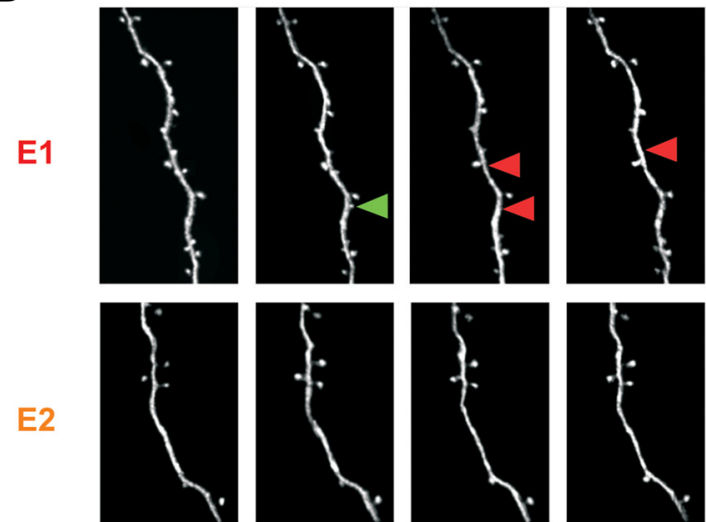

B1

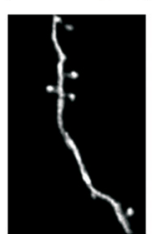

B2

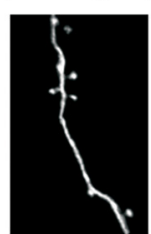

1

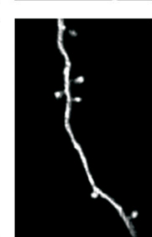

2
C
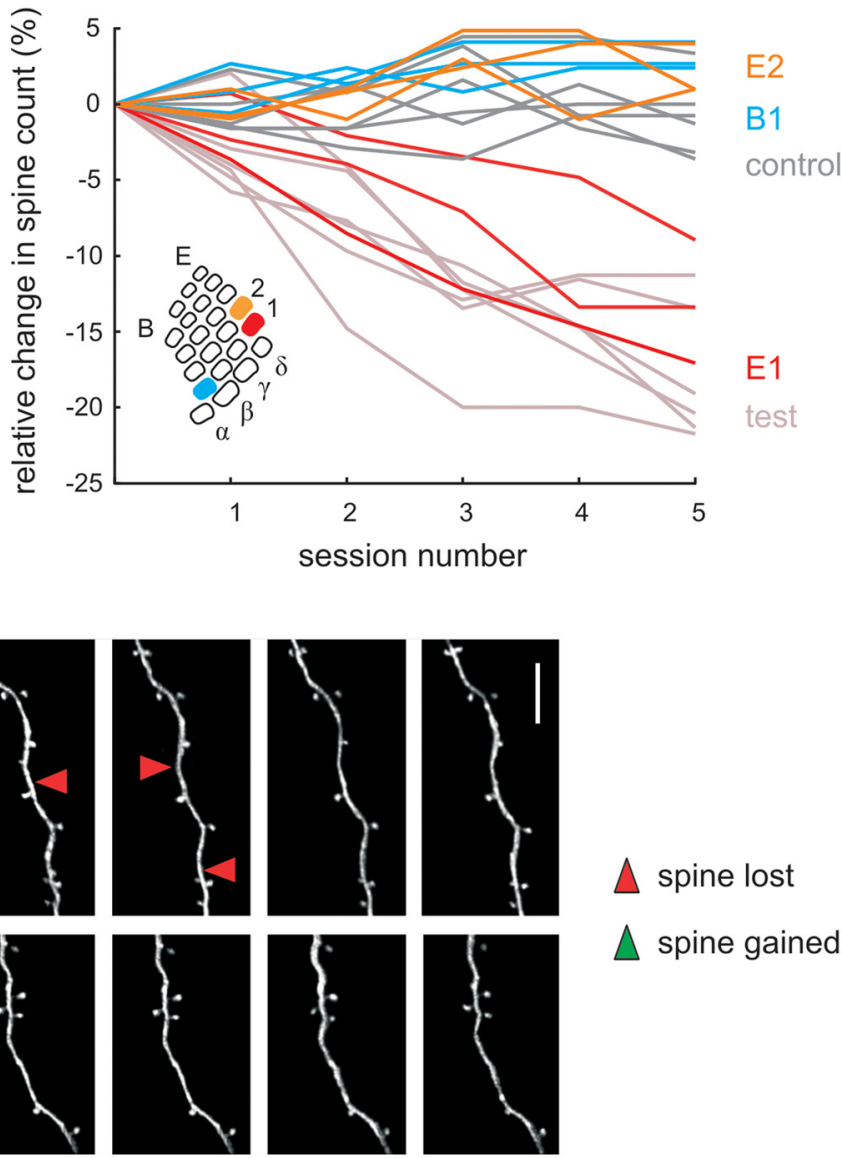

spine lost

spine gained

Figure 6. Learning-related spine loss is specific to principal barrel column E1, receiving the majority of CS whisker signals. $A$, Location of imaging sites for the E1 and E2 barrels with respect to the barrel field in three test mice (rows). Left, Two-photon imaging fields of view used to count spines framed by white boxes. YFP-labeled dendrites appear green and vessels labeled by intravenous bolus injection of Texas red are red. Scale bar, $50 \mu \mathrm{m}$. Center, Same but lower magnification. Scale bar, $100 \mu \mathrm{m}$. Right, Surface picture and circumference of intrinsic imaging signal obtained with stimulation of E1 (red) and E2 (orange) whisker. Sites of E1 and E2 barrel column are labeled in the second mouse-in the other cases, correspondence is equivalent. $\boldsymbol{B}$, Two-photon images of dendritic spines in E1 and E2. In E1, but not in E2, spine loss is observed during training. The green arrowhead indicates spine formation, red arrowheads indicate spine elimination. Scale bar, $10 \mu \mathrm{m}$. C, Relative reduction of spine counts found in E1 (red) versus E2 (orange) and B1 columns (blue) in the three animals. Light-colored lines replot data of all test and control mice as a reference (same as in Fig. 4C). Spine loss occurs in barrel column E1, but is absent in the adjacent column, E2, and the more distant column, B1. Inset: Schematic depicting the three investigated barrels E1 (red), E2 (orange), and B1 (blue) within the barrel field.

the sign of change in spine numbers is unclear. There are several published studies that monitored spine dynamics during learning. Most of them observed net spine formation: in motor cortex layer 1 during motor learning (Xu et al., 2009; Fu et al., 2012) and in auditory cortex layer 1 during fear conditioning (Moczulska et al., 2013). Another work studying fear conditioning observed the opposite sign: spine loss in layer 1 frontal association cortex (Lai et al., 2012). More recently, whisker-based sensorimotor learning was reported to lead to a small degree of spine formation in barrel cortex in L2/3 pyramidal cells (Kuhlman et al., 2014). Further, using histological sampling of spine numbers, spine formation during TTEBC was observed in the layer 4 barrels (Chau et al., 2014). The previous findings, together with our present finding of substantial spine loss in barrel cortex layer 1, suggest that the sign of spine number change can neither be predicted by the learning behavior nor uniquely determined by the particular cell, layer, or cortical area studied. Different layers/sites may have different computational roles, for example, sensory throughput versus association (perhaps layer 4 vs layer 1) and thus may experience different directions of spine numbers changes during the same task. In addition, the presence or absence of inhibitory synapses on dendritic spines may be decisive for spine elimination versus formation (Knott et al., 2002). Further, the crossed entry of CS (left face) and US (right face) to the brain used in our conditioning paradigm may have played some role for spine elimination. It has been suggested that learning sensory associations during fear conditioning are based on the fact that cortical responses tuned to relevant features/stimuli become stronger, but at the same time, more sparse (Gdalyahu et al., 2012). Such diverging tendencies may well be a principle element of learningrelated plasticity and may be reflected by opposite directions of spine number changes at different sites. The forgoing insights render it unlikely that the basis for learning can be related to single synaptic sites and/or mechanisms. However, our present results also argue against the opposite: that structural plasticity, even enabling the simplest of all learned behavior, an eyeblink, is distributed across the entire brain. We found completely unaffected spines even in barrel columns directly neighboring the principal one. This is surprising because adjacent columns do represent neighboring whiskers to a certain degree due to unspe- 
cific thalamic projections and dense corticocortical and corticosubcortical interconnections (Feldmeyer et al., 2013).

The spine loss observed here is tightly associated with the requirement of an intact barrel cortex and with spatially specific map plasticity. Galvez et al. (2007) showed that barrel cortex lesions abolish the acquisition of trace conditioning, but do not affect the acquisition of the delay paradigm. The same group showed that trace eyeblink conditioning induces enlargements of the columns receiving the signals from the stimulated whiskers, whereas those trained on a delay task do not (Galvez et al., 2011). The requirement of intactness of barrel cortex and presence of barrel extension for trace but not delay conditioning suggests that plastic changes of barrel cortex are a specific response to mnemonic components of the task and do not simply reflect the learned generation of CRs. Our results show that one cellular correlate of barrel extension is the pruning of layer 1 synapses on layer 5 pyramidal cells. Axons terminating at dendritic spines are believed to be largely excitatory (but see Knott et al., 2002). An important question is which excitatory inputs are pruned in layer 1 during TTEBC. The high columnar specificity of lack of spine loss in the neighboring barrel column revealed in the present study does not match the huge receptive fields (Ghazanfar and Nicolelis, 1999; Manns et al., 2004) and multiple columns spanning apical dendrites (Oberlaender et al., 2012a) of layer 5 cells. If the postsynaptic cells do not show morphological and functional specificity, the specificity of the pruned synapses must therefore originate from neurons mediating distinct column specific information to layer 1. Corticocortical terminals originating from the posterior-medial thalamic nucleus, primary motor cortex, and association tactile areas, which are known to project to barrel cortex layer 1, are unlikely to fulfill this requirement (Cauller and Connors, 1994; Cauller et al., 1998; Petreanu et al., 2012). In addition, infragranular layer neurons in the home column are unlikely candidates because they display the largest receptive fields within the column (Ghazanfar and Nicolelis, 1999; de Kock et al., 2007). Stronger contenders are spiny stellate and pyramidal cells in layers 4 and 2/3; both cell types project to layer 1 and have receptive fields largely restricted to one or very few whiskers (de Kock et al., 2007). Fittingly, dendrites of layer 2 pyramids, which are assumed to receive inputs comparable to that of layer 5 apical tufts, have been demonstrated to house a distinct subset of spines that are activated only by one whisker (Varga et al., 2011). In summary, the synaptic plasticity observed here seems to be involved in modifying column-specific processing.

What does that mean for the role of the barrel cortex in TTEBC? To approach this question, it is important to note first that activity persists throughout the trace period in prefrontal cortical areas (Siegel et al., 2012). Second, barrel cortex is absolutely critical for TTEBC: without it, no learning occurs at all. Third, the role of the barrel cortex during retention is clearly established, but is noncritical: it enhances CS signals with learning (Ward et al., 2012) and its blockade reduces, but does not entirely interrupt, learned behavior (Galvez et al., 2007). At first glance, this seems to be suggestive of a mere assisting role of the barrel cortex, providing a sensory throughput and elevating signal gain. This conclusion, however, may be premature: The spatial specificity of columnar extension and spine loss cannot be explained by a mere sensory throughput function because pseudo-conditioned mice receiving the same sensory input do not show the two aspects of plasticity. Therefore, there must be an interaction of the barrel column with downstream association centers during early learning phases to select the column for extension and spine plasticity guided by the learning success.

\section{References}

Boele H, Koekkoek SK, De Zeeuw CI (2010) Cerebellar and extracerebellar involvement in mouse eyeblink conditioning: the ACDC model. Front Cell Neurosci 3:19. CrossRef Medline

Cauller LJ, Connors BW (1994) Synaptic physiology of horizontal afferents to layer I in slices of rat SI neocortex. J Neurosci 14:751-762. Medline

Cauller LJ, Clancy B, Connors BW (1998) Backward cortical projections to primary somatosensory cortex in rats extend long horizontal axons in layer I. J Comp Neurol 390:297-310. CrossRef Medline

Chau LS, Prakapenka AV, Zendeli L, Davis AS, Galvez R (2014) Trainingdependent associative learning induced neocortical structural plasticity: a trace eyeblink conditioning analysis. PLoS One 9:e95317. CrossRef Medline

Chettih SN, McDougle SD, Ruffolo LI, Medina JF (2011) Adaptive timing of motor output in the mouse: the role of movement oscillations in eyelid conditioning. Front Integr Neurosci 5:72. CrossRef Medline

Clark RE, Manns JR, Squire LR (2001) Trace and delay eyeblink conditioning: contrasting phenomena of declarative and nondeclarative memory. Psychol Sci 12:304-308. CrossRef Medline

de Kock CPJ, Bruno RM, Spors H, Sakmann B (2007) Layer- and cell-typespecific suprathreshold stimulus representation in rat primary somatosensory cortex. J Physiol 581:139-154. CrossRef Medline

Diamond ME, Huang W, Ebner FF (1994) Laminar comparison of somatosensory cortical plasticity. Science 265:1885-1888. CrossRef Medline

Dombeck DA, Khabbaz AN, Collman F, Adelman TL, Tank DW (2007) Imaging large-scale neural activity with cellular resolution in awake, mobile mice. Neuron 56:43-57. CrossRef Medline

Feldman DE, Nicoll RA, Malenka RC (1999) Synaptic plasticity at thalamocortical synapses in developing rat somatosensory cortex: LTP, LTD, and silent synapses. J Neurobiol 41:92-101. CrossRef Medline

Feldmeyer D, Brecht M, Helmchen F, Petersen CC, Poulet JF, Staiger JF, Luhmann HJ, Schwarz C (2013) Barrel cortex function. Prog Neurobiol 103:3-27. CrossRef Medline

Feng G, Mellor RH, Bernstein M, Keller-Peck C, Nguyen QT, Wallace M, Nerbonne JM, Lichtman JW, Sanes JR (2000) Imaging neuronal subsets in transgenic mice expressing multiple spectral variants of GFP. Neuron 28:41-51. CrossRef Medline

Fox K (2002) Anatomical pathways and molecular mechanisms for plasticity in the barrel cortex. Neuroscience 111:799-814. CrossRef Medline

Fu M, Yu X, Lu J, Zuo Y (2012) Repetitive motor learning induces coordinated formation of clustered dendritic spines in vivo. Nature 483:92-95. CrossRef Medline

Galvez R, Weiss C, Weible AP, Disterhoft JF (2006) Vibrissa-signaled eyeblink conditioning induces somatosensory cortical plasticity. J Neurosci 26:6062-6068. CrossRef Medline

Galvez R, Weible AP, Disterhoft JF (2007) Cortical barrel lesions impair whisker-CS trace eyeblink conditioning. Learn Mem 14:94-100. CrossRef Medline

Galvez R, Cua S, Disterhoft JF (2011) Age-related deficits in a forebraindependent task, trace-eyeblink conditioning. Neurobiol Aging 32:19151922. CrossRef Medline

Gdalyahu A, Tring E, Polack PO, Gruver R, Golshani P, Fanselow MS, Silva AJ, Trachtenberg JT (2012) Associative fear learning enhances sparse network coding in primary sensory cortex. Neuron 75:121-132. CrossRef Medline

Ghazanfar AA, Nicolelis MA (1999) Spatiotemporal properties of layer V neurons of the rat primary somatosensory cortex. Cereb Cortex 9:348361. CrossRef Medline

Grutzendler J, Kasthuri N, Gan WB (2002) Long-term dendritic spine stability in the adult cortex. Nature 420:812-816. CrossRef Medline

Hefendehl JK, Milford D, Eicke D, Wegenast-Braun BM, Calhoun ME, Grathwohl SA, Jucker M, Liebig C (2012) Repeatable target localization for long-term in vivo imaging of mice with 2-photon microscopy. J Neurosci Methods 205:357-363. CrossRef Medline

Heiney SA, Wohl MP, Chettih SN, Ruffolo LI, Medina JF (2014) CerebellarDependent Expression of Motor Learning during Eyeblink Conditioning in Head-Fixed Mice. J Neurosci 34:14845-14853. CrossRef Medline

Holtmaat AJ, Trachtenberg JT, Wilbrecht L, Shepherd GM, Zhang X, Knott 
GW, Svoboda K (2005) Transient and persistent dendritic spines in the neocortex in vivo. Neuron 45:279-291. CrossRef Medline

Holtmaat A, Bonhoeffer T, Chow DK, Chuckowree J, De Paola V, Hofer SB, Hübener M, Keck T, Knott G, Lee WC, Mostany R, Mrsic-Flogel TD, Nedivi E, Portera-Cailliau C, Svoboda K, Trachtenberg JT, Wilbrecht L (2009) Long-term, high-resolution imaging in the mouse neocortex through a chronic cranial window. Nat Protoc 4:1128-1144. CrossRef Medline

Hübener M, Bonhoeffer T (2010) Searching for engrams. Neuron 67:363371. CrossRef Medline

Kalmbach BE, Ohyama T, Kreider JC, Riusech F, Mauk MD (2009) Interactions between prefrontal cortex and cerebellum revealed by trace eyelid conditioning. Learn Mem 16:86-95. CrossRef Medline

Knott GW, Quairiaux C, Genoud C, Welker E (2002) Formation of dendritic spines with GABAergic synapses induced by whisker stimulation in adult mice. Neuron 34:265-273. CrossRef Medline

Kraus N, Disterhoft JF (1982) Response plasticity of single neurons in rabbit auditory association cortex during tone-signalled learning. Brain Res 246: 205-215. CrossRef Medline

Kuhlman SJ, O'Connor DH, Fox K, Svoboda K (2014) Structural plasticity within the barrel cortex during initial phases of whisker-dependent learning. J Neurosci 34:6078-6083. CrossRef Medline

Lai CS, Franke TF, Gan WB (2012) Opposite effects of fear conditioning and extinction on dendritic spine remodelling. Nature 483:87-91. CrossRef Medline

Langer D, van 't Hoff M, Keller AJ, Nagaraja C, Pfäffli OA, Göldi M, Kasper H, Helmchen F (2013) HelioScan: a software framework for controlling in vivo microscopy setups with high hardware flexibility, functional diversity and extendibility. J Neurosci Methods 215:38-52. CrossRef Medline

Manns ID, Sakmann B, Brecht M (2004) Sub- and suprathreshold receptive field properties of pyramidal neurones in layers $5 \mathrm{~A}$ and $5 \mathrm{~B}$ of rat somatosensory barrel cortex. J Physiol 556:601-622. CrossRef Medline

Masino SA, Kwon MC, Dory Y, Frostig RD (1993) Characterization of functional organization within rat barrel cortex using intrinsic signal imaging through a thinned skull. Proc Natl Acad Sci U S A 90:9998-10002. CrossRef Medline

Moczulska KE, Tinter-Thiede J, Peter M, Ushakova L, Wernle T, Bathellier B, Rumpel S (2013) Dynamics of dendritic spines in the mouse auditory cortex during memory formation and memory recall. Proc Natl Acad Sci U S A.

Oberlaender M, de Kock CP, Bruno RM, Ramirez A, Meyer HS, Dercksen VI, Helmstaedter M, Sakmann B (2012a) Cell type-specific three-dimensional structure of thalamocortical circuits in a column of rat vibrissal cortex. Cereb Cortex 22:2375-2391. CrossRef Medline

Oberlaender M, Ramirez A, Bruno RM (2012b) Sensory experience restructures thalamocortical axons during adulthood. Neuron 74:648-655. CrossRef Medline
Petreanu L, Gutnisky DA, Huber D, Xu NL, O'Connor DH, Tian L, Looger L, Svoboda K (2012) Activity in motor-sensory projections reveals distributed coding in somatosensation. Nature 489:299-303. CrossRef Medline

Sakamoto T, Endo S (2010) Amygdala, deep cerebellar nuclei and red nucleus contribute to delay eyeblink conditioning in C57BL/6 mice. Eur J Neurosci 32:1537-1551. CrossRef Medline

Schwarz C, Hentschke H, Butovas S, Haiss F, Stüttgen MC, Gerdjikov TV, Bergner CG, Waiblinger C (2010) The head-fixed behaving rat - procedures and pitfalls. Somatosens Mot Res 27:131-148. CrossRef Medline

Siegel JJ, Kalmbach B, Chitwood RA, Mauk MD (2012) Persistent activity in a cortical-to-subcortical circuit: bridging the temporal gap in trace eyelid conditioning. J Neurophysiol 107:50-64. CrossRef Medline

Trachtenberg JT, Chen BE, Knott GW, Feng G, Sanes JR, Welker E, Svoboda K (2002) Long-term in vivo imaging of experience-dependent synaptic plasticity in adult cortex. Nature 420:788-794. CrossRef Medline

Tseng W, Guan R, Disterhoft JF, Weiss C (2004) Trace eyeblink conditioning is hippocampally dependent in mice. Hippocampus 14:58-65. CrossRef Medline

Varga Z, Jia H, Sakmann B, Konnerth A (2011) Dendritic coding of multiple sensory inputs in single cortical neurons in vivo. Proc Natl Acad Sci U S A 108:15420-15425. CrossRef Medline

Ward RL, Flores LC, Disterhoft JF (2012) Infragranular barrel cortex activity is enhanced with learning. J Neurophysiol 108:1278-1287. CrossRef Medline

Weinberger NM, Javid R, Lepan B (1993) Long-term retention of learninginduced receptive-field plasticity in the auditory cortex. Proc Natl Acad Sci U S A 90:2394-2398. CrossRef Medline

Weiss C, Disterhoft JF (2008) Evoking blinks with natural stimulation and detecting them with a noninvasive optical device: a simple, inexpensive method for use with freely moving animals. J Neurosci Methods 173:108 113. CrossRef Medline

Xu T, Yu X, Perlik AJ, Tobin WF, Zweig JA, Tennant K, Jones T, Zuo Y (2009) Rapid formation and selective stabilization of synapses for enduring motor memories. Nature 462:915-919. CrossRef Medline

Yamahachi H, Marik SA, McManus JN, Denk W, Gilbert CD (2009) Rapid axonal sprouting and pruning accompany functional reorganization in primary visual cortex. Neuron 64:719-729. CrossRef Medline

Yang G, Pan F, Gan WB (2009) Stably maintained dendritic spines are associated with lifelong memories. Nature 462:920-924. CrossRef Medline

Zuo Y, Lin A, Chang P, Gan WB (2005a) Development of long-term dendritic spine stability in diverse regions of cerebral cortex. Neuron 46:181189. CrossRef Medline

Zuo Y, Yang G, Kwon E, Gan WB (2005b) Long-term sensory deprivation prevents dendritic spine loss in primary somatosensory cortex. Nature 436:261-265. CrossRef Medline 